Words count: 2001 words

\title{
EXPERIMENTAL ASSESSMENT OF SAMPLING DISTURBANCE IN CALCAREOUS SILT
}

\author{
GUAN T. LIM ${ }^{*}$, JUBERT A. PINEDA ${ }^{\dagger}$, NATHALIE BOUKPETI ${ }^{*}$, ANDY FOURIE ${ }^{\diamond}$, \\ AND J. ANTONIO H. CARRARO ${ }^{+}$ \\ ${ }^{*}$ Centre for Offshore Foundation Systems (COFS) \\ The University of Western Australia \\ 35 Stirling Hwy, Crawley, Perth, Western Australia, Australia 6009 \\ e-mail: guan.lim@research.uwa.edu.au/nathalie.boukpeti@uwa.edu.au \\ ${ }^{\diamond}$ School of Civil, Environmental and Mining Engineering \\ The University of Western Australia \\ 35 Stirling Hwy, Crawley, Perth, Western Australia, Australia 6009 \\ e-mail: andy.fourie@uwa.edu.au \\ ${ }^{\dagger}$ ARC Centre of Excellence for Geotechnical Science and Engineering (CGSE) \\ The University of Newcastle \\ Callaghan campus, University Drive, Building EA, Newcastle, Australia 2308 \\ e-mail: jubert.pineda@newcastle.edu.au

\footnotetext{
${ }^{+}$Faculty of Engineering, Department of Civil and Environmental Engineering, Imperial College London (formerly at COFS),

528b, Skempton Building, South Kensington Campus, London, SW7 2AZ, UK

e-mail: antonio.carraro@imperial.ac.uk
}

\section{Key words:}

Sampling disturbance; calcareous silts; digital image correlation; physical modelling; penetration rates; strain field 


\begin{abstract}
A small-scale physical modelling program using particle image velocimetry and digital image correlation (PIV/DIC) techniques was designed to obtain a refined understanding of the disturbance experienced by calcareous silt during tube sampling. The influence of the sampler wall thickness (diameter to thickness ratio, $\mathrm{B} / \mathrm{t}$ ) and the tube penetration rate were evaluated by estimating displacement and strain fields around the tube sampler. The results indicate that sampling with a thin tube leads to a relatively narrow undisturbed zone located at the center of the tube, with a width slightly smaller than the tube radius. Opposite to what is suggested for soft clays, tube sampling tends to densify the calcareous silt. This aspect has an important influence on the assessment of sample quality in calcareous silt for offshore and onshore projects.
\end{abstract}




\section{INTRODUCTION}

The demand for offshore structures has increased over the last decades due to the positive outcomes of exploration into deeper water for oil and gas and the expanding growth of offshore renewable energy sectors. The costs to build these structures are very high due to the greater risks and challenges involved. Hence, it is crucial to have accurate geotechnical parameters of the site to be used in the geotechnical design. Most sampling campaigns in deep waters are performed using tube sampling methods such as Shelby tubes, as also occurs with onshore projects. Although soil disturbance due to tube sampling is inevitable, practitioners are obligated to assess the representativeness of soil specimens used in laboratory testing in order to minimize the uncertainty associated with the soil parameters used in geotechnical design. Only a few studies have evaluated the effects of tube sampling in silty soils (e.g., Long 2006; Pineda et al. 2012; Arroyo et al. 2015; Krage et al. 2016; Carroll \& Long 2017). Not surprisingly, the mechanisms of sampling disturbance in silty soils are still not well understood. Although some previous studies focussed on silty soils, calcareous silts, which represent materials commonly found in several offshore projects, have not been studied before.

This paper presents the results of small-scale physical modelling aimed at evaluating the effects of tube sampling in calcareous silt. The influence of the sampler thickness (diameter to thickness ratio, $\mathrm{B} / \mathrm{t}$ ), the drainage conditions as well as the sampler retrieval stage are evaluated in this study using displacement and strain fields around the tube sampler that were obtained using Particle Image Velocimetry (PIV) analysis (Stainer et al., 2015).

\section{TEST APPARATUS}

The physical model described below takes advantage of the symmetry of the problem to push-in half tubes in reconstituted calcareous silt against a transparent Perspex window. This model allows the use of the PIV technique to track soil displacements (and strains) during tube penetration as previously attempted by Yan et al. (2010) on reconstituted kaolin. A PIV box $(\mathrm{W}: \mathrm{L}: \mathrm{D}=0.22: 0.39: 0.33 \mathrm{~m}$ ) with transparent Perspex front and back panels was used as a consolidation chamber. The Perspex window contained equally spaced markers which were used to convert measurements in pixels to field measurements in $\mathrm{mm}$. The box was fitted into a steel strongbox used in centrifuge tests, as shown in Figure 1. Tube sampling was performed using an electrically driven actuator (two degrees of freedom) controlled using the in-house software PACS ${ }^{\circledR}$ (De Catania et al., 2010). Half-tube samplers were fabricated by cutting standard $50 \mathrm{~mm}$ diameter aluminium tubes into two halves and attaching a connecting bolt at 
the top of the half-tube. Tube samplers with a cutting toe angle of $15^{\circ}$ were used. The vertical edges of the half tubes were lined with a rubber membrane to provide a good seal between the tube and the Perspex window with minimum friction.

Images were acquired using a charge-coupled device sensor camera (Allied Vision Technologies Prosilica GC2450C) with Gigabit Ethernet connectivity for fast data transfer. An in-house lighting system consisting of LED panels was set-up to ensure the light was uniform, bright and of similar colour as natural light.

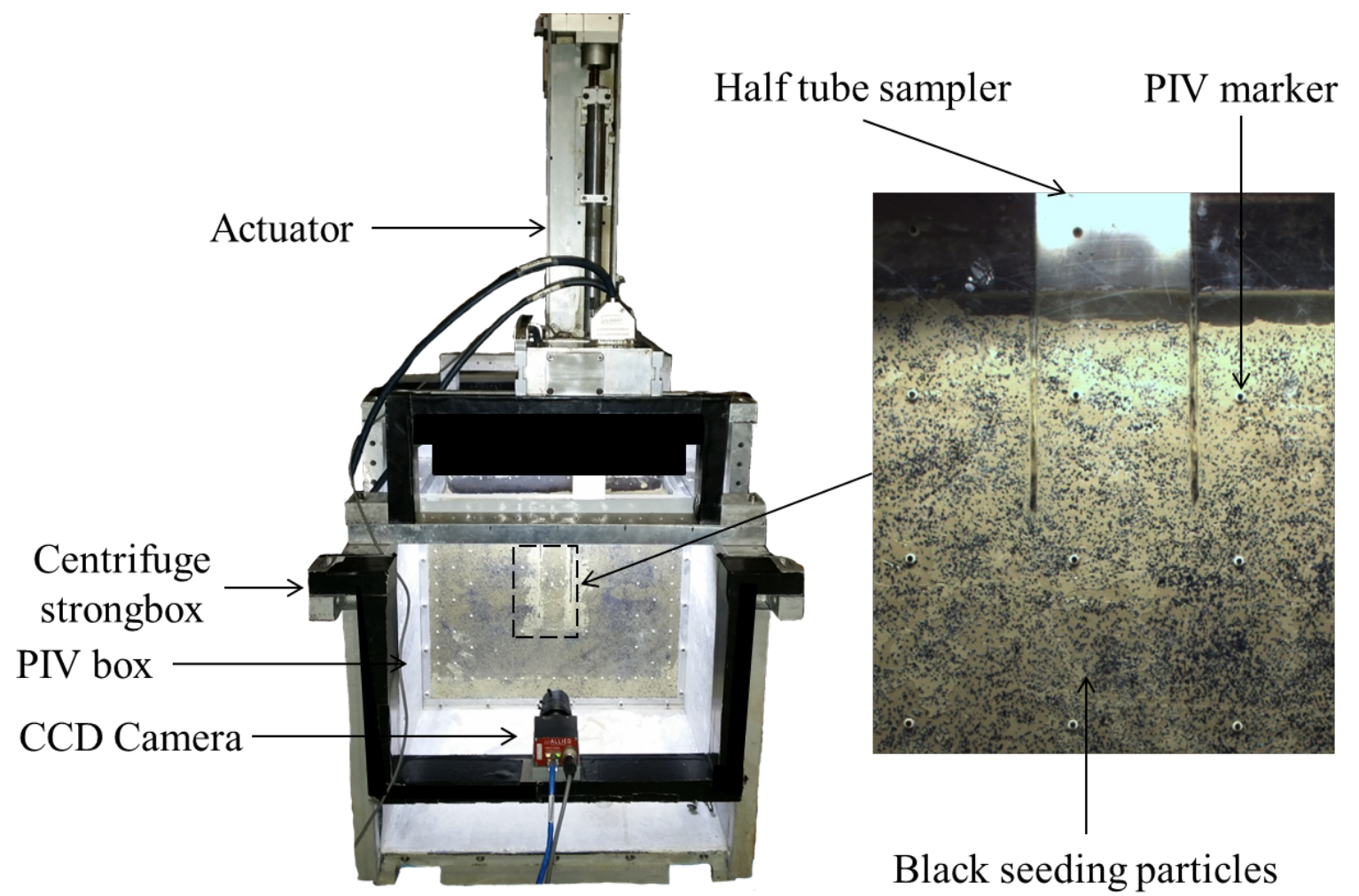

Figure 1: Experimental set-up for tube sampling

\section{MATERIAL AND EXPERIMENTAL PROCEDURES}

\subsection{Sample preparation}

Calcareous silt (24\% clay, $66 \%$ silt and $10 \%$ fine sand) obtained from the North West Shelf of Australia was tested in this study with its index properties shown in Table 1. Reconstituted silt was created by mixing the soil with synthetic seawater ( $35 \mathrm{~g}$ of NaCl per litre of deionised water) to produce a slurry with initial water content around $110 \%$. The slurry was mixed for 48 hours before pouring it into the PIV box. A geotextile layer on top and bottom of the sample allowed double drainage conditions during consolidation. One-dimensional consolidation was carried out in stages up to a vertical stress of $50 \mathrm{kPa}$. The slurry was 
consolidated in three layers. The first two layers were compressed to $35 \mathrm{kPa}$ whereas the maximum vertical stress was achieved after pouring the third layer. After consolidation, the silt was unloaded to $5 \mathrm{kPa}$ before testing. The final water content of the consolidated silt was approximately $51 \%$.

Table 1: Index properties of the calcareous silt tested in this study

\begin{tabular}{|l|c|}
\hline Liquid limit, $\mathrm{w}_{\mathrm{L}}(\%)$ & 52 \\
\hline Plasticity index, $\mathrm{I}_{\mathrm{P}}(-)$ & 22 \\
\hline Specific gravity, $\mathrm{G}_{\mathrm{s}}(-)$ & 2.69 \\
\hline Initial water content of slurry, $\mathrm{w}_{\text {slurry }}(\%)$ & 110 \\
\hline Particle size distribution (clay / silt / sand) (\%) & $24 / 66 / 10$ \\
\hline Coefficient of uniformity, $\mathrm{C}_{\mathrm{u}}\left[\mathrm{D}_{60} / \mathrm{D}_{10}\right]$ & 46 \\
\hline Coefficient of curvature, $\mathrm{C}_{\mathrm{c}}\left[\left(\mathrm{D}_{30}\right)^{2} /\left(\mathrm{D}_{10} \times \mathrm{D}_{60}\right)\right]$ & 1.2 \\
\hline
\end{tabular}

Figure 2 shows the testing configuration, which included two sampling tests in each PIV box. Two boxes (four sampling tests) were prepared and tested in this study. Black seeding particles were used to create the necessary surface texture for PIV analysis. The spreading pattern was compared and matched upon the given image texture with an artificial seeding ratio of 0.5 (Stainer and White, 2013). Before tube sampling, the undrained shear strength, $\mathrm{s}_{\mathrm{u}}$, profile of the reconstituted sample was estimated via mini piezoball testing (piezoball diameter, $\mathrm{D}_{\mathrm{B}}$ : $20 \mathrm{~mm}$ and penetration speed: $2 \mathrm{~mm} / \mathrm{s}$ ). After the sampling simulation, the walls of the PIV box were dismantled and a cubic block sample $(\sim 100 \mathrm{~mm}$ side) was cut from the mid-height of the box to perform one-dimensional Constant Rate of Strain (CRS) compression tests.

Undrained shear strength derived from piezoball tests (Colreavy et al., 2015) using $\mathrm{N}_{\text {ball }}$ of 11 show similar $\mathrm{s}_{\mathrm{u}}$ profiles for both PIV boxes $(\sim 20 \mathrm{kPa})$ over the first $100 \mathrm{~mm}$, below which a slight decrease in $\mathrm{s}_{\mathrm{u}}(\sim 17 \mathrm{kPa})$ is observed in Box 2 (Figure 3a). It suggests a slightly less homogeneity compared to the soil in Box 1. This behaviour is confirmed by the larger compressibility obtained from CRS tests (Figure $3 b$ ) for the sample trimmed from Box 2. 


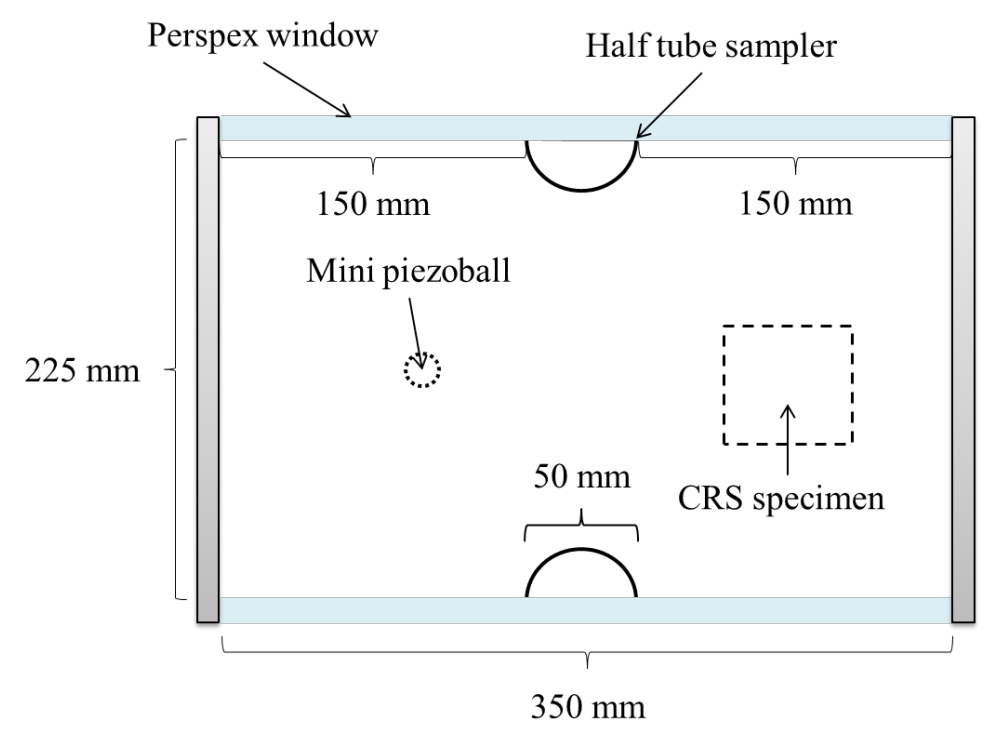

Figure 2: Plan view of mini piezoball and tube samplers' penetration locations

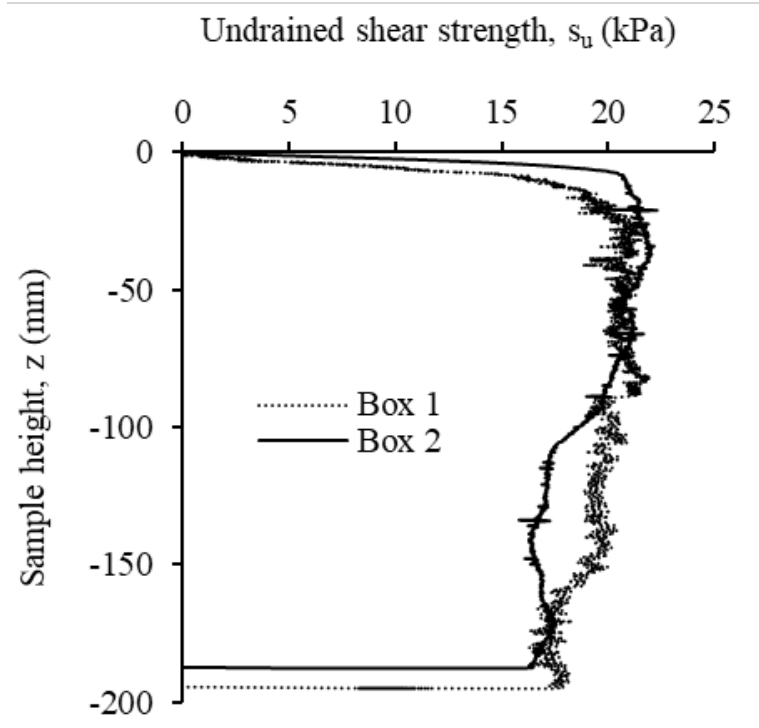

(a)

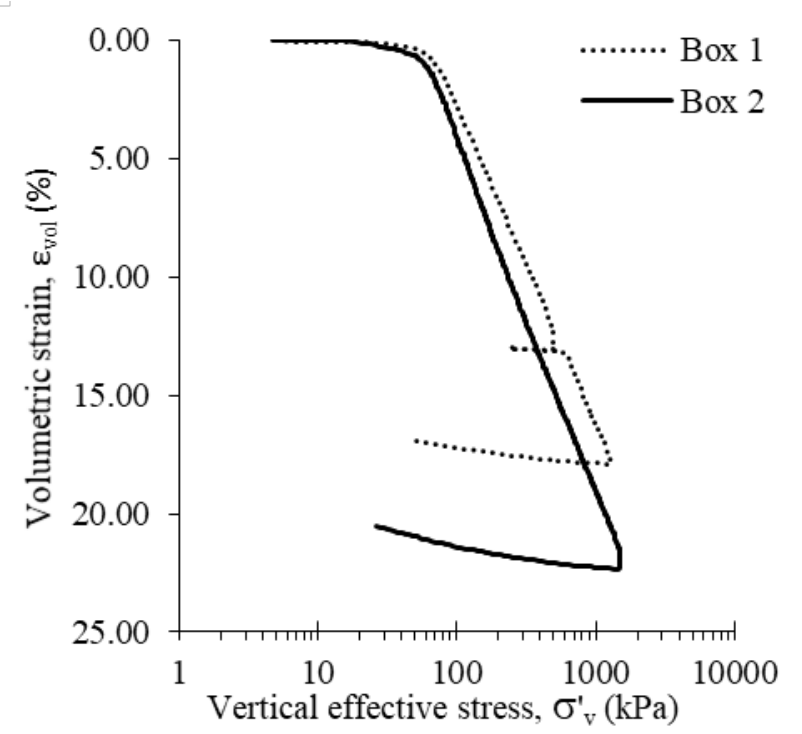

(b)

Figure 3: (a) Undrained shear strength with depth from mini-piezoball test, (b) CRS test results

\subsection{Sampling tests}

The edges and interior of the tube sampler were greased with silicon oil before it was attached to the actuator. To seal the contact between the tube and the window, the sampler was pushed against the Perspex window until a contact load of $5 \mathrm{~N}$ was registered. Then, the tube sampler was pushed vertically at a prescribed rate over a length of $140 \mathrm{~mm}$. At the end of the penetration, a resting period of five minutes was imposed to allow for pore pressure dissipation, prior to sampler retrieval. Subsequently, a second sampling test was performed on the opposite 
side of the PIV box (Figure 2). Details of tube geometry and penetration rate used are outlined in Table 2.

Table 2: Parameters for tube sampling simulations

\begin{tabular}{|c|l|c|c|c|c|c|c|c|}
\hline \multirow{2}{*}{ Box } & \multirow{2}{*}{$\begin{array}{c}\text { Sampling } \\
\text { tests }\end{array}$} & $\begin{array}{c}\text { Outside } \\
\text { diameter, } \\
\mathrm{B}\end{array}$ & $\begin{array}{c}\text { Thickness, } \\
\mathrm{t}\end{array}$ & $\begin{array}{c}\text { Cutting } \\
\text { toe } \\
\text { angle, } \\
\text { OCA }\end{array}$ & $\begin{array}{c}\text { Internal } \\
\text { diameter } \\
\text { of cutting } \\
\text { shoe, } \mathrm{D}_{\mathrm{i}}\end{array}$ & $\begin{array}{c}\text { Area } \\
\text { ratio, AR } \\
\left(\mathrm{B}^{2}-\mathrm{D}_{\mathrm{i}}^{2}\right) / \\
\mathrm{Di}^{2}\end{array}$ & $\mathrm{~B} / \mathrm{t}$ & $\begin{array}{c}\text { Penetration } \\
\text { rate }\end{array}$ \\
\cline { 3 - 10 } & $(\mathrm{mm})$ & $(\mathrm{mm})$ & $\left({ }^{\circ}\right)$ & $(\mathrm{mm})$ & $(-)$ & $(-)$ & $\mathrm{mm} / \mathrm{s}$ \\
\hline 1 & TN_UD & 50 & 1.25 & 15 & 47.5 & 0.11 & 40 & 2.0 \\
\hline 1 & TK_UD* & 50 & 2.5 & 15 & 45 & 0.23 & 20 & 2.0 \\
\hline 2 & TN_PD & 50 & 1.25 & 15 & 47.5 & 0.11 & 40 & 0.4 \\
\hline 2 & TK_PD & 50 & 2.5 & 15 & 45 & 0.23 & 20 & 0.4 \\
\hline
\end{tabular}

Note: TN-thin tube; TK-thick tube; PD-partially-drained and UD-undrained

* Results are not interpreted for this test as some damage to the tube sealant lead to erroneous responses.

A camera resolution of $2448 \times 2050$ pixels at ten frames per second was used during tube penetration and extraction. This corresponds to $6-7$ pixels per mm for a field of view (FOV) of the image of $370 \times 320 \mathrm{~mm}$. Thus, the frame rate per second (fps) of the camera was selected such that a movement less than $0.2 \mathrm{~mm}$ occurred between two successive images. Frame rates of ten and two fps were used for the sampling tests conducted at penetration rates of $2 \mathrm{~mm} / \mathrm{s}$ and $0.4 \mathrm{~mm} / \mathrm{s}$, respectively. The analysis of the images presented below was carried out using the software GeoPIV-RG. The results of test TK_UD are not described here as unreliable results were obtained in this case due to inappropriate sealing between the tube and the Perspex window.

\section{RESULTS}

\subsection{Effects of the $B / t$ ratio}

Penetration of thin and thick tube samplers into a soil mass is expected to cause different deformation patterns. This effect may be evaluated by using tube samplers with different $\mathrm{B} / \mathrm{t}$ ratios. Although it has been suggested that samplers with $\mathrm{B} / \mathrm{t}>40$ provide good quality specimens in soft soils (Ladd and DeGroot, 2003) experimental evidence comes mainly from soft clays. Figure $4 \mathrm{a}$ shows the displacement fields estimated for samplers with $\mathrm{B} / \mathrm{t}$ ratios of 40 [thin(TN)] and 20 [thick(TK)] pushed into the soil mass at $0.4 \mathrm{~mm} / \mathrm{s}$ [partially-drained (PD)] (tests TN_PD and TK_PD in Table 1). The thick sampler produces larger displacements and a wider disturbed zone compared with the thin tube. The shear strain contours presented in Figure $4 \mathrm{~b}$ confirm the wider zone of shear straining caused by the thick sampler $(B / t=20)$ which 
extends over more than half the sample radius. Maximum shear strains around $20 \%$ and $12 \%$ are observed at the sidewall for thick and thin samplers, respectively.

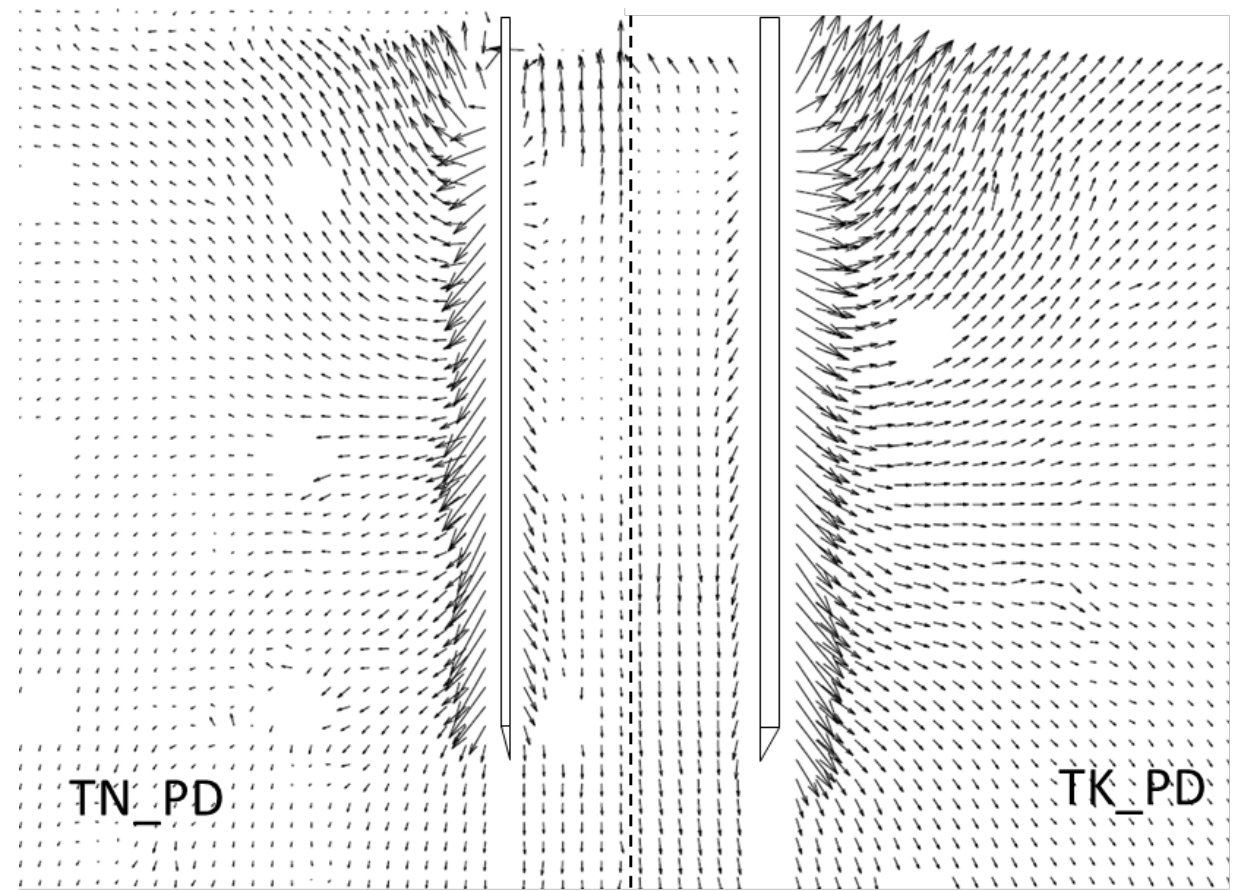

(a)

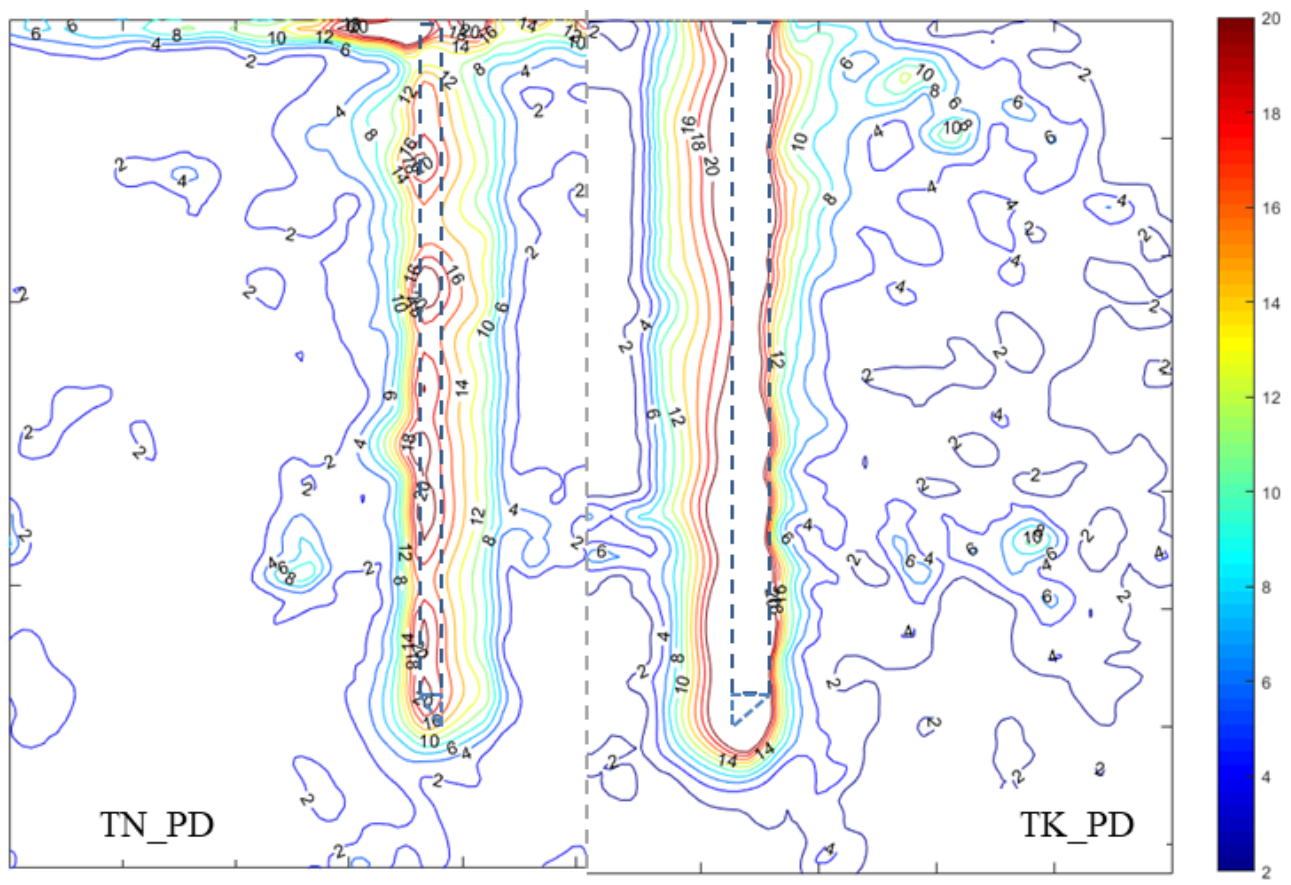

(b)

Figure 4. Displacement fields and shear strain contours for thin $(B / t=40)$ and thick $(B / t=20)$ tubes pushed-in under partially drained conditions, showing (a) displacement fields and (b) shear strain contours. 


\subsection{Effects of the penetration rate}

Penetration rates of $2.0 \mathrm{~mm} / \mathrm{s}$ and $0.4 \mathrm{~mm} / \mathrm{s}$ were adopted in this study to simulate two drainage scenarios: undrained and partially drained conditions, respectively. According to Finnie \& Randolph (1994), values of normalised velocity $\mathrm{V}>30$ and $\mathrm{V}<0.01$ delimit undrained and fully drained penetration conditions, respectively. The normalised velocity, $\mathrm{V}$, is estimated as (Finnie \& Randolph 1994):

$$
V=\frac{v D_{e}}{c_{v}}
$$

where $\mathrm{v}$ is the velocity of the penetrating object, $\mathrm{D}_{\mathrm{e}}$ is the equivalent diameter of the penetrating object and $c_{v}$ is the coefficient of consolidation of the soil. $D_{e}$ is the diameter of a hypothetical cylinder, which has the same planar area as the penetrating object (Cassidy, 2012). For a half tube sampler of outer diameter $B$ and thickness $t, D_{e}$ is defined as:

$$
D_{e}=\sqrt{2 B t}
$$

By using an average value of $c_{v}=25 \mathrm{~m}^{2} /$ year, estimated from the two CRS tests shown in Figure $3 b$, the penetration rates adopted in this study provide values of $V=40$ (undrained) and $\mathrm{V}=7$ (partially drained).

The displacement fields at the end of penetration for thin tubes $(\mathrm{B} / \mathrm{t}=40)$ pushed into the soil at undrained and partially drained conditions (tests TN_UD and TN_PD in Table 1) are shown in Figure 5a. Large upwards displacements (heave) occured close to the ground surface whereas compressive displacements are observed at the tube sidewalls as the sampler penetrates deeper into the soil. Displacements are slightly smaller in the undrained case over the central zone of the sampler. Undrained tube penetration produces less shear deformation inside the tube as shown in Figure 5 b. Maximum shear strains at the silt-tube interface were $\sim 10 \%$ and $\sim 20 \%$ for undrained and partially drained penetration, respectively. It may be noted that, for the case of undrained penetration, the contour of shear strain equal to $2 \%$ defines an area of a width slightly smaller than the tube radius. This zone, which may be considered of good quality for laboratory testing, is smaller in the case of partially drained penetration as shown in Figure $5 \mathrm{~b}$. Displacements and strain fields for partially drained tube penetration (TN_PD) shown in Figure 5 correspond to estimations made for the right side of the sampler. Comparison against the left side (TN_PD in Figure 4) indicates that displacements and strain fields are not completely symmetric with respect to the centreline of the sampler. 


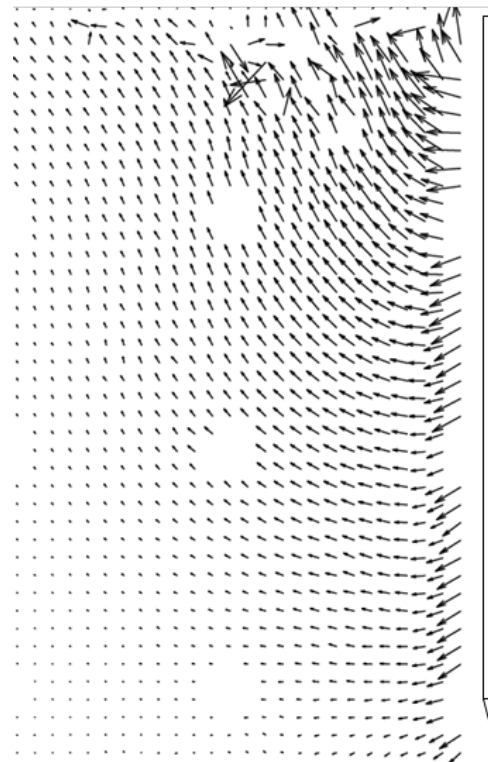

TN UD

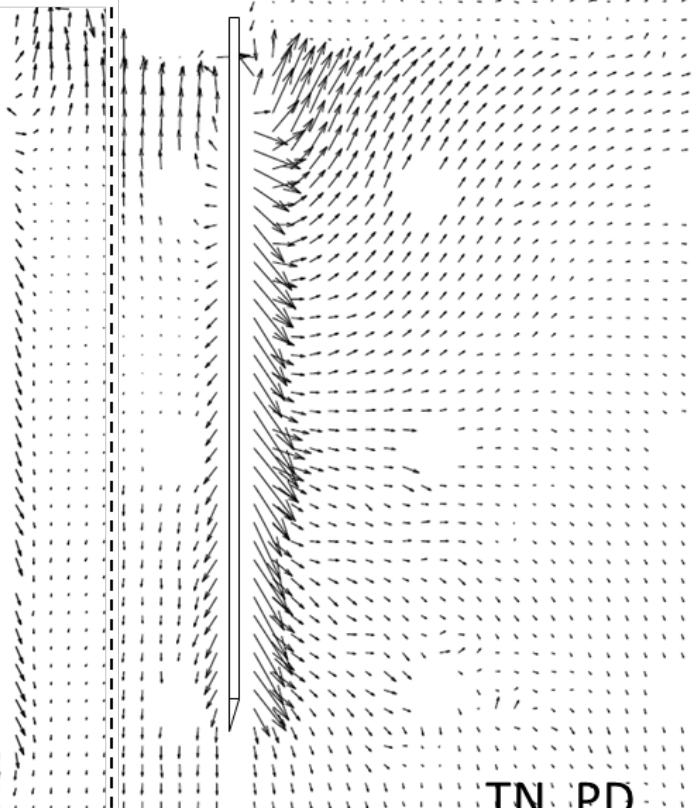

TN PD

(a)

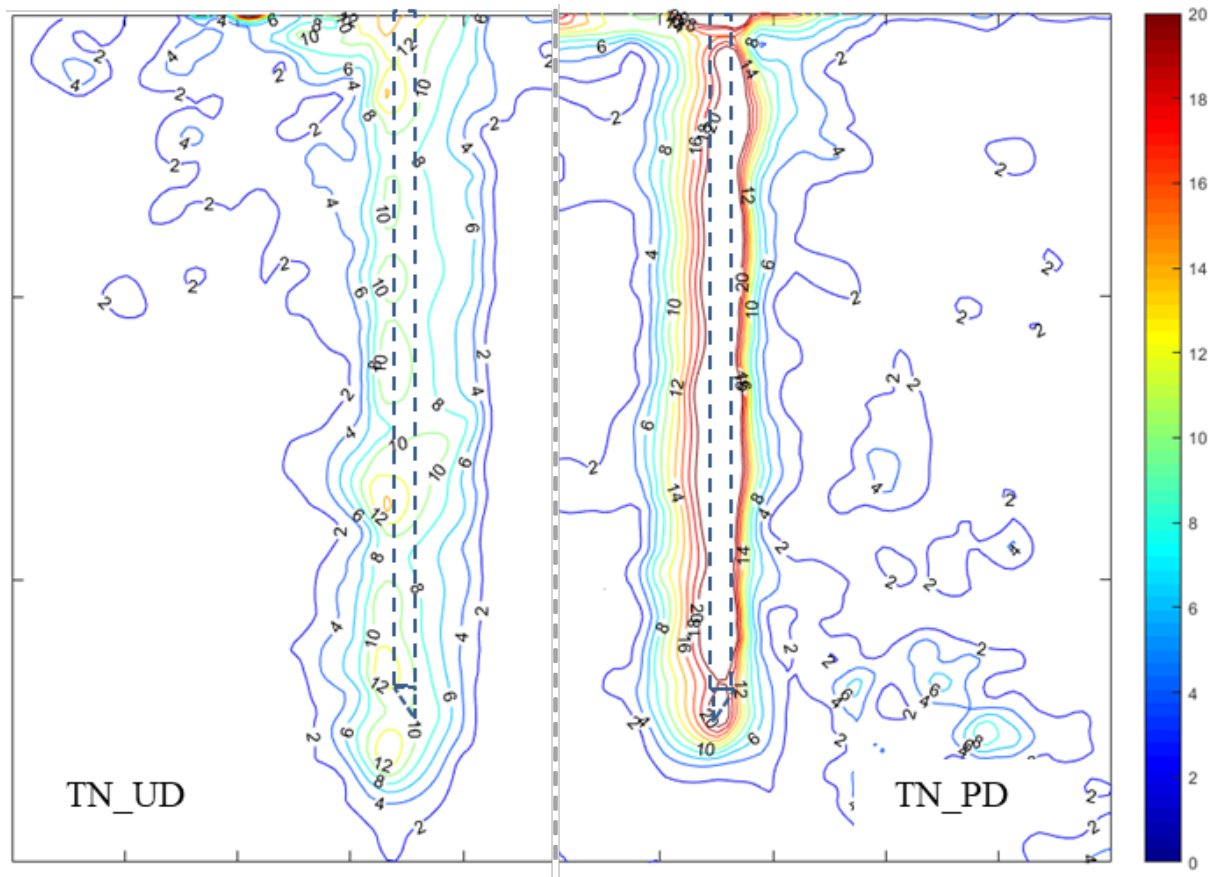

(b)

Figure 5. Displacement fields and shear strain contours for thin tubes pushed-in at undrained (PN_UD) and partially drained (TN_PD) conditions, showing (a) displacement fields and (b) shear strain contours. 


\subsection{Vertical and volumetric strain paths}

Vertical and volumetric strains caused by tube penetration were estimated for two soil elements, one located close to the tube sidewall (S) and the other close to the tube centreline (C) (see Figure 6a). It can be noted that the origin of the normalised depth $(\mathrm{z}=0)$ coincides with the location of the sampler tip. Figures $6 \mathrm{~b}$ and $6 \mathrm{c}$ show the vertical strains at the sidewall and centreline respectively, and Figures $6 \mathrm{~d}$ and $6 \mathrm{e}$ show volumetric strains for these same locations respectively. Two trends are observed in Figure 6. Specimens located at the sidewall (S) show very large vertical and volumetric compressive deformations, which produce a nonsymmetric deformation path (see Figures $6 \mathrm{~b}$ and $6 \mathrm{~d}$ ). Penetration of thick samplers under partially drained conditions produces larger strains, with values up to 10 times larger than those at the centreline. Estimated vertical and volumetric strains at the centreline show the trend previously reported by Baligh et al. (1987) (see Figure 6c, where results according to Baligh are shown for thin and thick samplers, designated as B-TN and B-TK respectively): compression ahead of the sampler, extension behind the sampler tip and compression for soil elements located at $\mathrm{z}>\mathrm{B}$. A smaller and more symmetric strain path is induced at the centreline (C) by pushing a thin sampler under undrained conditions. Although the symmetry of the analytical solution for the vertical strain path reported by Baligh et al. (1987) is not observed experimentally (as previously reported by Clayton \& Siddique, 2001; Hover et al., 2013), good agreement is observed in Figure 6c irrespective of the $B / t$ value.

Volumetric strains shown in Figures 6d and 6e clearly shows that tube penetration causes soil densification (due to the accumulation of compression strains) with larger values observed when thick tubes are pushed-in under partially drained conditions.

\subsection{Effects of sampler retrieval}

Sampler retrieval plays an important role in sample disturbance. Because of the very large soil movements that occurred during this stage, unrealistic results were obtained from GeoPIV-RG and therefore neither displacement fields or strain contours are presented here. Nevertheless, the digital images shown in Figure 7 give a qualitative insight into the mechanisms that occur during sampler retrieval using open samplers. Three mechanisms may be recognized: (i) the progressive development of a shear plane at the sampler tip, (ii) the soil heave at the bottom of the borehole (due to the interaction between the uplift force and soil suction), and (iii) the creation of tension cracks, due to the loss of lateral support for the soil located at the bottom of the sampler, which leads to low soil recovery. The soil recovery for 
TN_UD, TN_PD and TK_PD (sampled length $=140 \mathrm{~mm}$ ) were approximately $100 \%, 64 \%$ and $34 \%$, respectively.

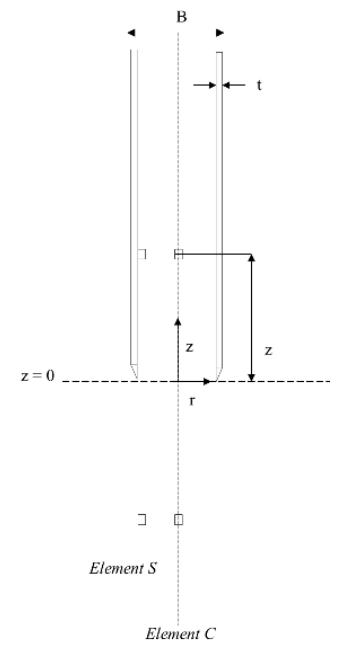

(a)
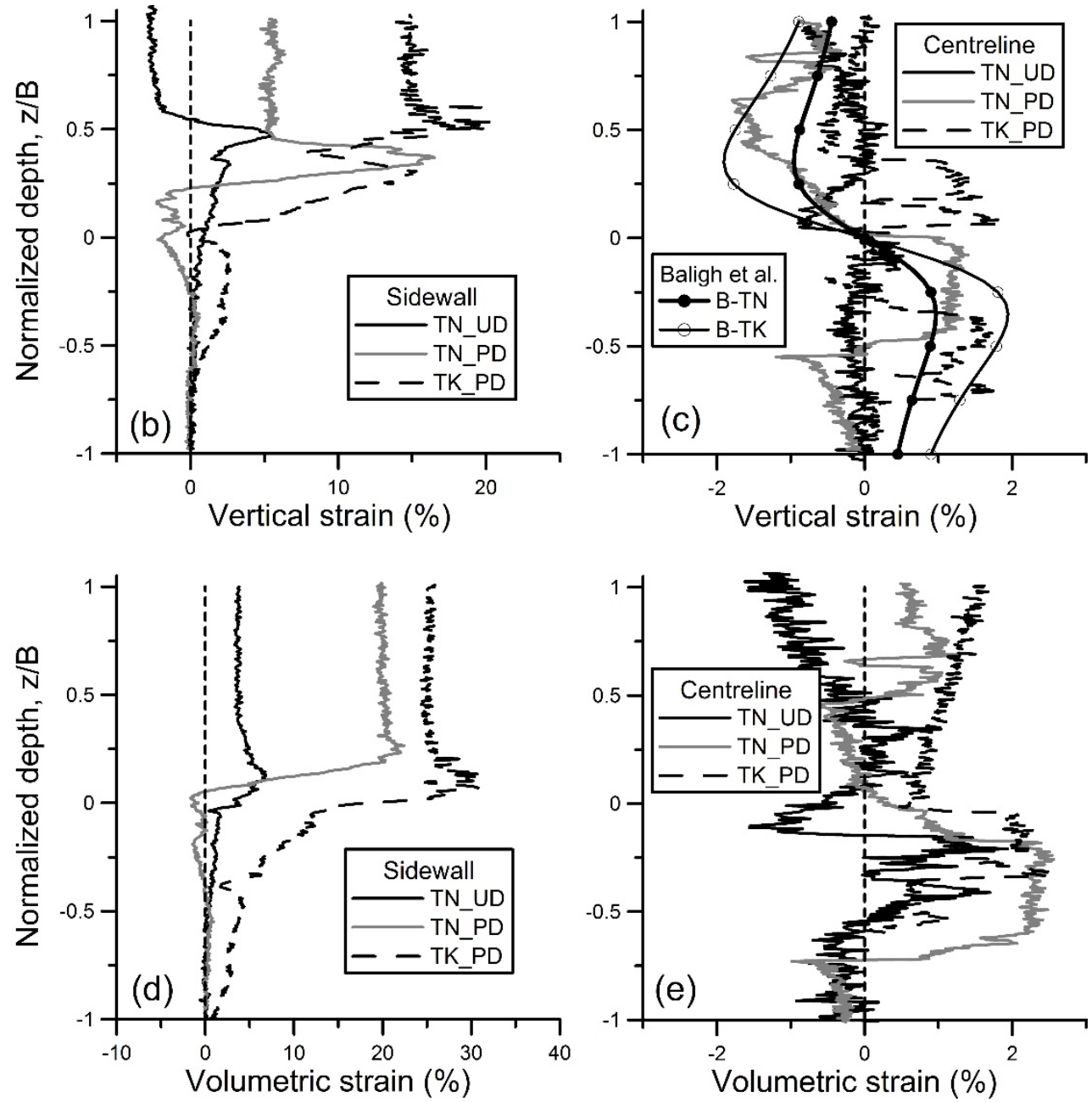

Figure 6: Vertical and volumetric strain paths. (a) location of the element at sidewall, $\mathrm{S}$ and centreline, C; (b) Vertical strains at the sidewall, S; (c) Vertical strains at the centreline, C; (d) Volumetric strain at the sidewall, S and (e) Volumetric strains at the centreline, C. 


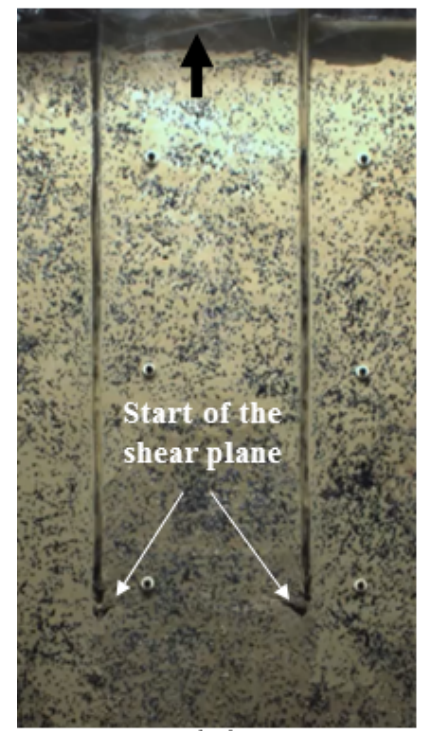

(a)

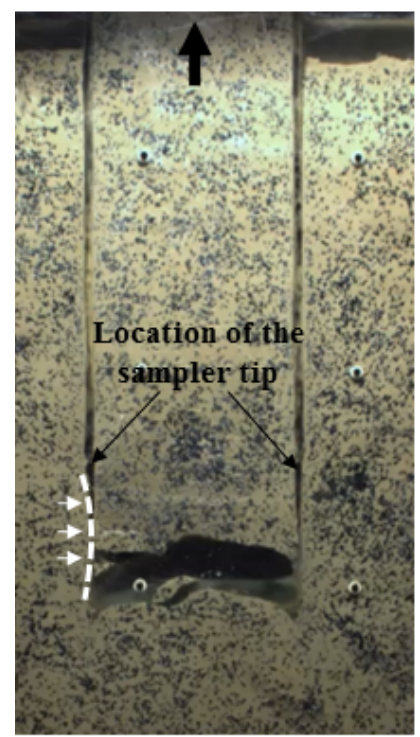

(c)

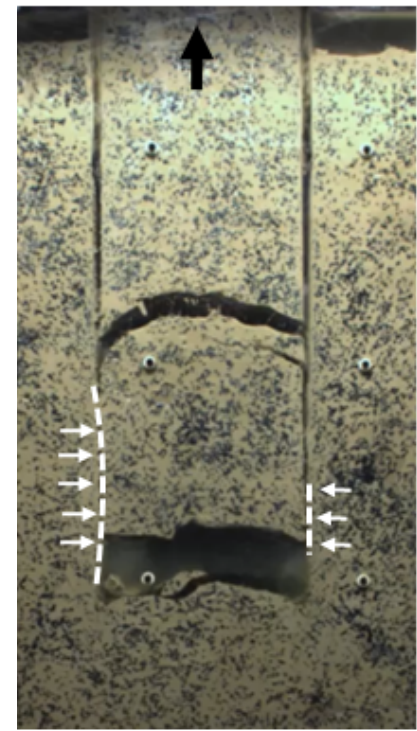

(e)

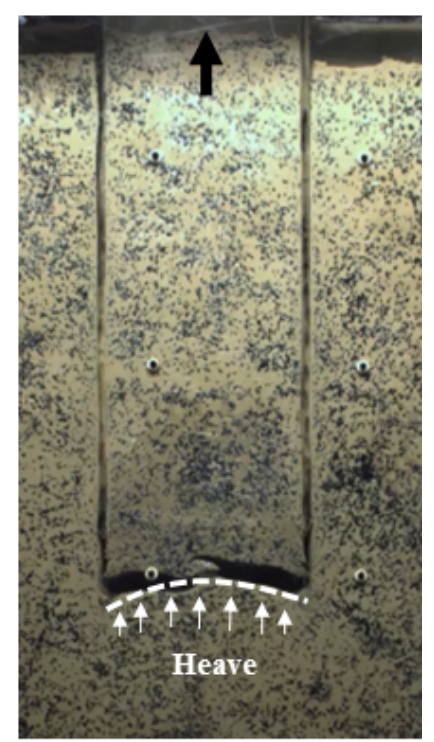

(b)

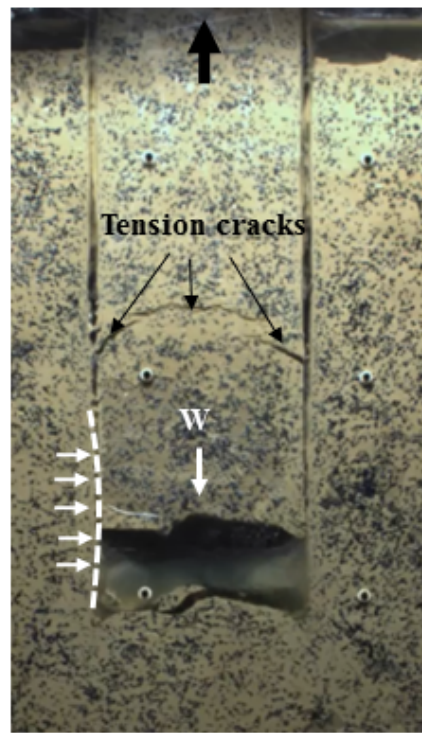

(d)

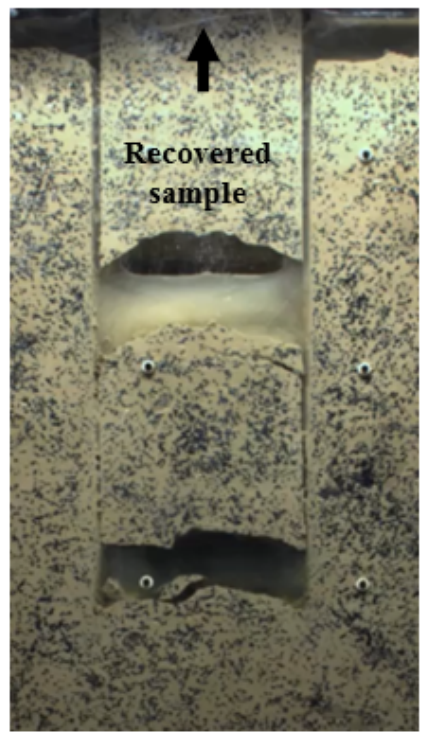

(f)

Figure 7: Effects of sampler retrieval 


\section{CONCLUDING REMARKS}

Physical modelling results presented in this paper have provided important insights into the mechanisms of sampling disturbance in calcareous silts. Although it has been confirmed that thin samplers reduce soil disturbance, the zone exposed to small shear strains is still less than half of the tube radius. Larger disturbance is caused by partially drained tube penetration. Hence, appropriate tube penetration rates, estimated via Eq. 1, should be adopted in practice to ensure undrained conditions and reduce soil disturbance. Considering that typical specimen diameters range from around 40 to $50 \mathrm{~mm}$, the experimental results described above show that the use of $50 \mathrm{~mm}$ samplers in practice produces highly disturbed specimens for laboratory testing, irrespective of their B/t ratio. Consequently, the need for large diameter piston samplers to reduce soil disturbance, including that caused by suction effects at the bottom of the sample during sampler retrieval, is evident. Opposite to what is suggested for soft clay, tube sampling tends to densify the calcareous silt and therefore to overestimate the undrained shear strength.

There are additional factors not considered here such as the excess pore pressure induced during penetration/extraction as well as the influence of the sampler diameter. A largescale physical model for tube sampling is currently under development to study these factors. Further study is required to investigate sampling with larger diameter tubes, higher sampling rates, a sampler with piston, as well as sampler extraction methods.

\section{ACKNOWLEDGEMENTS}

The research presented here forms part of the activities of the Centre for Offshore Foundation Systems (COFS), currently supported as a node of the Australian Research Council Centre of Excellence for Geotechnical Science and Engineering (CGSE) (grant CE110001009). The authors are grateful for support by all contributing partners to the ARC CGSE. These partners include Fugro AG, Coffey Geotechnics, Douglas Partners and the NSW Science Leveraging Fund. 


\section{REFERENCES}

Arroyo, M, Pineda, J, Sau, N, Devincenzi, M \& Pérez, N 2015, 'Sample quality examination on silty soils', in 16th European Conf. on Soil Mechanics and Geotechnical Engineering, Thomas Telford Ltd, Edinburgh, Scotland, pp. 2873-2878.

Baligh, MM, Azzouz, AS \& Chin, CT 1987, 'Disturbances due to "ideal" tube sampling', Journal of Geotechnical Engineering, vol. 113, no. 7, pp. 739-757.

Carroll, R \& Long, M 2017, 'Sample Disturbance Effects in Silt', Journal of Geotechnical and Geoenvironmental Engineering, vol. 143, no. 9, p. 04017061.

Cassidy, MJ 2012, 'Experimental observations of the penetration of spudcan footings in silt', Géotechnique, vol. 62, no. 8, pp. 727-732.

Clayton, CRI \& Siddique, A 2001, 'Tube sampling disturbance-forgotten truths and new perspectives', in Proceedings of The Institution of Civil Engineers Geootechnical Engineering.

Colreavy, C, O'Loughlin, CD \& Randolph, MF 2015, 'Experience with a dual pore pressure element piezoball', International Journal of Physical Modelling in Geotechnics, pp. 118.

De Catania, S., Breen, J., Gaudin, C. and White, D.J., 2010, 'Development of a multiple axis actuator control system', In Proceedings of the 7th International Conference on Physical Modelling in Geotechnics, Zurich, Switzerland, Vol. 1, pp. 325-330.

Finnie, I \& Randolph, M 1994, 'Punch-through and liquefaction induced failure of shallow foundations on calcareous sediments', in Proceedings of International Conference on Behaviour of Offshore Structures, Boston, MA, pp. 217-230.

Hover, ED, Guymer, I \& Ni, Q 2013, 'Investigation of centreline strain path during tube penetration using transparent soil and particle image velocimetry', Géotechnique Letters, vol. 3, no. April-June, pp. 37-41.

Krage, C, Albin, B, DeJong, J \& DeGroot, D 2016, 'The influence of in situ effective stress on sample quality for intermediate soils', in Proc. 5th international conference in geotechnical and geophysical site characterization, ISC5, McConnell, Kelly \& Lehane (eds), Gold Coast, Australia, Vol 1, pp. 565-570.

Ladd CC and DeGroot DJ 2003, 'Recommendedpracticefor soft ground site characterization', The Arthur Casagrande Lecture, In $12^{\text {th }}$ Pan. Conf. on Soil Mech. and Geotech. Eng., MIT, vol 1, pp 3-57

Long, M 2006, 'Sample disturbance effects on medium plasticity clay/silt', in Proc. Inst. Civ. Eng. Geotech. Eng, pp. 99-111.

Pineda, JA, Arroyo, M, Sau, N, Gens, A \& Pérez, N 2013, 'Testing block samples from silty deposits', in 4th Int. Conf. On Geotechnical and Geophysical Site Characterisation (ISC'4), Taylor \& Francis, Brazil, pp. 1815-1823.

Stanier, SA, Blaber, J, Take, WA \& White, DJ 2015, 'Improved image-based deformation measurement for geotechnical applications', Canadian Geotechnical Journal, vol. 53, no. 5 , pp. 727-739.

Stanier, SA \& White, DJ 2013, 'Improved Image-Based Deformation Measurement in the Centrifuge Environment', Geotechnical Testing Journal, vol. 36, no. 6, pp. pp. 915-928.

Yan, W, Ng, I \& Cheuk, C 2010, 'Displacement field around an open-tube sampling', in Proc. 7th Int. Conf. Physical Modelling in Geotechnics, Zurich, Switzerland, pp. 411-416. 